\title{
Sistem Pendukung Keputusan Pemilihan Paket Wedding Organizer Menggunakan Metode SAW (Simple Additive Weighting)
}

\author{
Rizka Ristiana $^{[1]}$, Yuwan Jumaryadi ${ }^{[2]^{*}}$ \\ Program Studi Sistem Informasi, Fakultas Ilmu Komputer, Universitas Mercu Buana \\ J1. Meruya Selatan No.1, Kembangan, Jakarta Barat \\ Jakarta, Indonesia \\ E-mail: ristianarizka@gmail.com ${ }^{[1]}$, yuwan.jumaryadi@mercubuana.ac.id ${ }^{[2]}$
}

\begin{abstract}
Preparing for a wedding is of course not easy, there is a lot to pay attention to so the event goes according to plan. There are several factors that must be considered, including the budget owned by the prospective bride and groom, because the budget decides what kind of concept the wedding organizer will give. There is a need for a system that can make it easier for customers to choose the wedding package that suits their wishes but does not take a long time. The SAW method is needed to find the weighted sum of the performance ratings for each alternative in all attributes. To provide recommendations for the desired package, there are several criteria. The criteria are calculated using the SAW method. The results of the ranking obtained V3 = 0.683 and $V 6=0.706$. With the results of this ranking, it can be concluded that $\mathrm{V} 6$ is the alternative package chosen as the best alternative for service users with the weight of each criterion determined by the service user. What is expected from this research is the design results of the wedding organizer package selection used by customers in determining the best package as desired.
\end{abstract}

Keywords-Decision Support System, Wedding Organizer, Simple Additive Weighting, Marriage, Wedding Organizer Package Selection

Abstrak - Mempersiapkan acara pernikahan tentu saja tidak mudah, banyak yang harus diperhatikan agar acara berjalan sesuai rencana. Ada beberapa faktor yang harus diperhatikan diantaranya yaitu anggaran yang dimiliki oleh calon pengantin, karena dari anggaran tersebut ysang memutuskan seperti apa konsep yang diberi oleh wedding organizer. Diperlukan adanya sistem yang bisa memudahkan pelanggan dalam pemilihan paket wedding yang sesuai dengan keinginan tetapi tidak mengabiskan waktu yang lama. metode SAW diperlukan untuk mencari penjumlahan terbobot dari rating kinerja pada setiap alternative di semua atribut. Untuk memberikan rekomendasi paket yang diinginkan ada beberapa kriteria. Kriteria dihitung menggunakan metode SAW. Hasil dari perankingan diperoleh $\mathrm{V3}=0,683$ dan $\mathrm{V} 6$ $=0,706$. Dengan hasil perankingan tersebut, dapat disimpulkan bahwa V6 adalah alternative paket yang dipilih sebagai alternative terbaik pengguna jasa dengan bobot setiap kriteria yang ditentukan oleh pengguna jasa. Yang diharapkan dari Penelitian ini yaitu hasil rancangan pemilihan paket wedding organizer yang digunakan untuk para pelanggan dalam menetukan paket terbaik sesuai dengan yang diinginkan.
Kata Kunci- Sistem Pendukung Keputusan, Wedding Organizer, Simple Additive Weighting, Pernikahan, Pemilihan Paket Wedding Organizer

\section{PENDAHULUAN}

Pada era modern dan serba cepat saat ini, masyarakat sering menghadapi problematika dalam mengatur acara pernikahan. Pernikahan merupakan hal yang amat dinanti oleh semua pasangan. Semua persiapan untuk menghadapi pernikahan dibutuhkan agar pengantin memiliki khayalan pernikahan yang megah, mengesankan dan tidak akan terlupakan [1]. Tidak hanya bagi pengantin, namun bagi para tamu undangan telah yang hadir.

Tidak mudah dalam mempersiapkan suatu acara pernikahan, harus banyak persiapan agar suatu acara berjalan sesuai dengan rencana yang telah ditentukan, diantaranya survey tempat berlangsungnya acara dan katering. atau memperhatikan detil-detil yang harus dipersiapkan apabila cara diselengarakan sesuai dengan suku daerah tertentu, sehingg akan sangat menghabiskan waktu dan tenaga, mempersiapkan mental dan fisik yang sebaiknya dilakukan oleh para calon pengantin dikarenakan waktu acara yang semakin dekat [2]. oleh karena itu banyak calon mempelai yang lebih memilih memakai jasa wedding organizer dikarenakan karna tidak banyak waktu dan wedding organizer akan membantu keseluruhan dari persiapan pernikahan hingga akhir acara [3].

Banyak faktor yang harus dipertimbangkan untuk memilih jasa wedding organizer. salah satunya yaitu anggaran yang harus dimiliki calon pengantin. karna dari anggaran tersebutlah yang memutuskan seperti apa konsep dari wedding organizer. anggaran menjadi salah satu tolak ukur yang sifatnya kuantitatif, biasanya dengan harga yang murah para calon pegantin tergiur dan tidak mempertimbangkan seperti apa konsep serta reputasi dari wedding organizer tersebut [1].

Diperlukan adanya sistem untuk memilih paket yang sesuai dengan kebutuhan anggaran pengguna jasa, yang dapat mudahkan pelanggan dalam pemilihan paket pernikahan. Untuk memberikan penawaran paket pernikahan sebagai penyedia jasa wedding organizer menginginkan agar pemilihan 
beberapa kriteria yang akan dijadikan bobot dalam pemilihan paket pernikahan dipilih sendiri oleh pemakai jasa agar kriteria yang diinginkan sesuai dengan keinginan pemakai jasa.

Penggabungan antara unsur kuantitatif dan kualitatif dalam keputusan dapat dibantu dengan sistem pendukung keputusan (SPK) dimana pengertiannya merupakan penyediaan informasi, proses manipulasi data, dam pemodelan yang disediakan oleh sistem informasi.sebuah masalah yang tidak terstruktur [1].

Metode yang digunakan untuk menyelesaikan suatu permasalahan dalam proses pengambilan keputusan pemilihan paket wedding organizer adalah Simple Additive Weighting (SAW). Alasan digunakannya metode SAW karena metode ini memiliki sebuah keunggulan. diantaranya yaitu dapat dengan mudah dimengerti, lebih fleksibel dan dapat menyelesaikan berbagai masalah yang kompleks serta melakukan pembelajaran berdasarkan dari pengalaman manusia dalam menyelesaikan suatu masalah.

Metode ini merupakan penentuan terbobot, diberikan pembobotan untuk masing-masing kriteria sehingga memperoleh hasil perankingan. yang mempunyai nilai tertinggi merupakan pilihan prioritas agar pemilihan serta perhitungan kriteria tersebut dapat dilakukan dengan cepat, tepat dan mendekati kesesuaian kriteria yang diinginkan oleh pengguna jasa [4]. Pada penelitian ini diterapkan metode SAW dengan mengambil 6 kriteria sebagai atribut untuk proses pengolahan data yaitu : dekorasi, catering, busana dan rias pengantin, dokumentasi, jumlah tamu dan harga paket. Penggunaan Metode SAW telah digunakan untuk berbagai pengambilan keputusan seperti untuk pemilihan dosen terbaik [5]. dan pemilihan hotel di kota Palembang [6].

\section{LANDASAN TEORI}

\section{A. Sistem Pendukung Keputusan}

Sistem Pendukung Keputusan merupakan penyediaan informasi, proses manipulasi data, dan pemodelan yang disediakan oleh sistem informasi untuk membuat keputusan yang fleksibel [7][8]. Dengan menggunakan sistem pendukung keputusan, maka dapat membantu dalam proses pengambilan keputusan [9].

\section{B. Simple Additive Weighting}

Metode Simple Additive Weighting merupakan penentuan terbobot, diberikan pembobotan untuk masing-masing kriteria sehingga memperoleh hasil perankingan. metode ini memiliki 2 atribut yaitu benefit dan cost. Metode ini harus melakukan proses normalisai keputusan (x) agar bisa dipertimbangkan ke semua alternatif yang ada [10][11].

Formula untuk melakukan normalisasi yaitu:

$$
r_{i j}=\left\{\begin{array}{l}
\frac{x_{i j}}{\operatorname{Max} x_{i j}} \\
\frac{\operatorname{Min} x_{i j}}{x_{i j}}
\end{array}\right.
$$

Keterangan:

$r_{i j}=$ rating kinerja ternormalisasi

$x_{i j}=$ nilai maximum kriteria

$\operatorname{Max} x_{i j}=$ nilai minimun kriteria

$\operatorname{Min} x_{i j}=$ nilai terkecil dari kriteria

Nilai preferensi untuk setiap alternatif (Vi) yaitu :

$$
V_{i}=\sum_{j=1}^{n} w_{j} r_{i j}
$$

Keterangan:

$V_{i} \quad$ rangking untuk setiap alternatif

$w_{j}=$ bobot dari setiap kriteria

$r_{i j}=$ rating kinerja ternormalisasi

Nilai Vi yang lebih besar mengindikasikan bahwa alternatif Ai lebih terpilih.

\section{METODE PENELITIAN}

\section{A. Metode Pengembangan Sistem}

Metodologi pengembangan system yang digunakan dalam penelitian ini adalah waterfall, atau yang biasanya disebut dengan Classic Life Cycle. Metode waterfall melakukan pendekatan secara sistematis dan berurutan. Berikut ini merupakan tahapan-tahapan dari metode waterfall [12]:


Gambar 1. Metode Waterfall

\section{Communication}

Tahap ini merupakan tahap awal dari penelitian, dimana dilakukan proses komunikasi terlebih dahulu kepada pihak Gatari Catering untuk mengetahui proses bisnis yang sedang berjalan dan data-data yang dibutuhkan.

\section{Planning}

Pada tahap ini dilakukan proses perencanaan dalam penentuan rancangan sistem pemilihan paket yang dibangun dan penjadwalan kerja yang akan dilaksanakan.

\section{Modeling}

Pada tahap ini merupakan tahap perancangan dan pemodelan arsitekur sistem yang berfokus pada rancangan uml, rancangan basis data, rancangan user interface, rancangan masukan dan rancangan keluaran. Tujuannya yaitu untuk mengetahui gambaran besar dari sistem yang akan di bangun.

\section{Construction}

Pada tahap ini dilakukan pengembangan terhadap 
perancangan yang telah dibuat.

\section{Deployment}

Pada tahap ini dilakukan proses pengujian terhadap pengembangan aplikasi yang telah dilakukan.

\section{B. Metode Pengumpulan Data}

\section{Observasi}

Yaitu dengan dating langsung ke Gatari Catering guna mendapatkan informasi yang dibutuhkan.

\section{Wawancara}

Yaitu data yang didapat dari bagian yang berwenang secara langsung.

\section{Studi Pustaka}

Mendapatkan informasi tambahan untuk pembuatan sistem dengan membaca dan meringkas berbagai macam jurnal dan buku yang membahas materi khususnya tentang metode Simple Additive Weighting.

\section{HASIL DAN PEMBAHASAN}

Acuan penentuan kriteria dalam kebutuhan informasi atas sistem pendukung keputusan pemilihan paket wedding adalah Ci. Diperoleh 6 kriteria dalam perhitungan SAW [13]. Seperti tertera pada Tabel 1

TABLE I. TABEL KRITERIA

\begin{tabular}{|c|c|c|}
\hline Kriteria (C) & Keterangan & Atribut \\
\hline C1 & Dekorasi & Cost \\
\hline C2 & Katering & Cost \\
\hline C3 & Busana dan Rias Pengantin & Cost \\
\hline C4 & Dokumentasi & Cost \\
\hline C5 & Jumlah Tamu & Benefit \\
\hline C6 & Harga Paket & Cost \\
\hline
\end{tabular}

Dengan rating kecocokan untuk C1 sampai C4 serta C6 sebagai atribut keuntungan oleh pemilik usaha pada setiap kriteria, dinilai dengan 1 sampai 5, yaitu:

$$
\begin{aligned}
& 1=\text { Sangat Tidak Penting } \\
& 2=\text { Tidak Penting } \\
& 3=\text { Cukup Penting } \\
& 4=\text { Penting } \\
& 5=\text { Sangat Penting }
\end{aligned}
$$

Untuk C5 dan C6 diberikan data riil yaitu jumlah tamu dan harga paket. Berdasarkan wawancara yang dilakukan dengan penyedia jasa, bobot kriteria yang digunakan dalam penentian seperti pada Tabel II berikut ini.

TABLE II.

NILAI PREFERENSI (W) SETIAP KRITERIA

\begin{tabular}{|c|c|}
\hline Kriteria & Bobot \\
\hline C1 & $15 \%=0,15$ \\
\hline C2 & $15 \%=0,15$ \\
\hline C 4 & $15 \%=0,15$ \\
\hline C5 & $15 \%=0,15$ \\
\hline C6 & $20 \%=0,2$ \\
\hline
\end{tabular}

Setelah memberikan nilai dari kriteria dan bobot, selanjutnya adalah melakukan perhitungan dan mendapatkan output yang diharapkan dari laporan ini. Pada Tabel III menjelaskan perhitungan dan keluaran yang diharapkan:

TABLE III.

TABEL ALTERNATIF

\begin{tabular}{|c|c|c|c|c|c|c|}
\hline \multirow{2}{*}{ Alternatif } & \multicolumn{7}{|c|}{ Kriteria } \\
\cline { 2 - 7 } & C1 & C2 & C3 & C4 & C5 & C6 \\
\hline Paket I & 5 & 4 & 2 & 3 & 1000 & 95.000 .000 \\
\hline Paket II & 2 & 3 & 1 & 2 & 500 & 44.000 .000 \\
\hline Paket III & 4 & 3 & 4 & 2 & 1000 & 70.000 .000 \\
\hline Paket IV & 4 & 3 & 3 & 2 & 800 & 81.000 .000 \\
\hline Paket V & 4 & 3 & 5 & 3 & 800 & 58.000 .000 \\
\hline Paket VI & 3 & 2 & 2 & 3 & 600 & 49.000 .000 \\
\hline
\end{tabular}

Pemberian nilai 1-5 juga diberikan pada tingkat dari kepentingan kriteria, yaitu:

$1=$ Sangat Tidak Penting,

$2=$ Tidak Penting

$3=$ Cukup Penting,

$4=$ Penting,

$5=$ Sangat Penting

\section{Tahap Pertama}

Tahap pertama menentukan matrix keputusan Berdasarkan data alternatif, diperoleh matrix keputusan (X). sebagai berikut:

$$
X=\left[\begin{array}{cccccc}
5 & 4 & 2 & 3 & 1000 & 95000000 \\
2 & 3 & 1 & 2 & 500 & 44000000 \\
4 & 3 & 4 & 2 & 1000 & 70000000 \\
4 & 3 & 3 & 2 & 800 & 81000000 \\
4 & 3 & 5 & 3 & 800 & 58000000 \\
3 & 2 & 2 & 3 & 600 & 49000000
\end{array}\right]
$$

2. Tahap Kedua

Tahap kedua yaitu menghitung matrix yang ternormalisasi

Nomalisasi C1:

$$
\begin{aligned}
& \mathrm{R} 1=\min \{5,2,4,4,43\} / 5=2 / 5=0,4 \\
& \mathrm{R} 2=\min \{5,2,4,4,43\} / 2=2 / 2=1 \\
& \mathrm{R} 3=\min \{5,2,4,4,43\} / 4=2 / 4=0,5 \\
& \mathrm{R} 4=\min \{5,2,4,4,43\} / 4=2 / 4=0,5 \\
& \mathrm{R} 5=\min \{5,2,4,4,43\} / 4=2 / 4=0,5 \\
& \mathrm{R} 6=\min \{5,2,4,4,43\} / 3=2 / 3=0,67
\end{aligned}
$$

Normalisasi C2:

$\mathrm{R} 1=\min \{4,3,3,3,3,2\} / 4=2 / 4=0,5$

$\mathrm{R} 2=\min \{4,3,3,3,3,2\} / 3=2 / 3=0,67$

$\mathrm{R} 3=\min \{4,3,3,3,3,2\} / 3=2 / 3=0,67$

$\mathrm{R} 4=\min \{4,3,3,3,3,2\} / 3=2 / 3=0,67$

$\mathrm{R} 5=\min \{4,3,3,3,3,2\} / 3=2 / 3=0,67$

$\mathrm{R} 6=\min \{4,3,3,3,3,2\} / 2=2 / 2=1$

Normalisasi C3:

$\mathrm{R} 1=\min \{2,1,4,3,5,2\} / 2=1 / 2=0,5$

$\mathrm{R} 2=\min \{2,1,4,3,5,2\} / 1=1 / 1=1$

$\mathrm{R} 3=\min \{2,1,4,3,5,2\} / 4=1 / 4=0,25$

$\mathrm{R} 4=\min \{2,1,4,3,5,2\} / 3=1 / 3=0,3$

$\mathrm{R} 5=\min \{2,1,4,3,5,2\} / 5=1 / 5=0,2$

$\mathrm{R} 6=\min \{2,1,4,3,5,2\} / 3=1 / 2=0,5$

\section{Normalisasi C4:}




$$
\begin{aligned}
& \mathrm{R} 1=\min \{3,2,2,2,3,3\} / 3=2 / 3=0,67 \\
& \mathrm{R} 2=\min \{3,2,2,2,3,3\} / 2=2 / 2=1 \\
& \mathrm{R} 3=\min \{3,2,2,2,3,3\} / 2=2 / 2=1 \\
& \mathrm{R} 4=\min \{3,2,2,2,3,3\} / 2=2 / 2=1 \\
& \mathrm{R} 5=\min \{3,2,2,2,3,3\} / 3=2 / 3=0,67 \\
& \mathrm{R} 6=\min \{3,2,2,2,3,3\} / 3=2 / 3=0,67
\end{aligned}
$$

Normalisasi C5:

$\mathrm{R} 1=1000 /(\operatorname{Max})\{1000,500,1000,800,800,600\}=$ $1000 / 1000=1$

$\mathrm{R} 2=500 /(\operatorname{Max})\{1000,500,1000,800,800,600\}=$ $500 / 1000=0,5$

$\mathrm{R} 3=1000 /(\operatorname{Max}) \quad\{1000,500,1000,800,800,600\}=$ $1000 / 1000=1$

$\mathrm{R} 4=800 /(\operatorname{Max})\{1000,500,1000,800,800,600\}=$ $800 / 1000=0,8$

$\mathrm{R} 5=800 /($ Max $) \quad\{1000,500,1000,800,800,600\}=$ $800 / 1000=0,8$

$\mathrm{R} 6=600 /(\operatorname{Max}) \quad\{1000,500,1000,800,800,600\}=$ $600 / 1000=0,6$

\section{Normalisasi C6:}

$\mathrm{R} 1=\min \{44000000,49000000,58000000,70000000$, $81000000,95000000\} / 95000000=44000000 / 95000000=$ 0,4

$\mathrm{R} 2=\min \{44000000,49000000,58000000,70000000$, $81000000,95000000\} / 44000000=44000000 / 44000000=$ 1

$\mathrm{R} 3=\min \{44000000,49000000,58000000,70000000$, $81000000,95000000\} / 70000000=44000000 / 70000000=$ 0,6

$\mathrm{R} 4=\min \{44000000,49000000,58000000,70000000$, $81000000,95000000\} / 81000000=44000000 / 81000000=$ 0,5

$\mathrm{R} 5=\min \{44000000,49000000,58000000,70000000$, $81000000,95000000\} / 58000000=44000000 / 58000000=$ 0,7

$\mathrm{R} 6=\min \{44000000,49000000,58000000,70000000$, $81000000,95000000\} / 49000000=44000000 / 49000000=$ 0,8

$$
\mathrm{R}=\left[\begin{array}{cccccc}
0,4 & 0,5 & 0,5 & 0,67 & 1 & 0,4 \\
1 & 0,67 & 1 & 1 & 0,5 & 1 \\
0,5 & 0,67 & 0,25 & 1 & 1 & 0,6 \\
0,5 & 0,67 & 0,3 & 1 & 0,8 & 0,5 \\
0,5 & 0,67 & 0,2 & 0,67 & 0,8 & 0,7 \\
0,67 & 1 & 0,5 & 0,67 & 0,6 & 0,8
\end{array}\right]
$$

\section{Tahap Ketiga}

Tahap ketiga yaitu penentuan nilai vector bobot. penentuan nilai vector bobot yang setiap bobot kriterianya ditentukan oleh pengguna jasa, dilambangkan dengan (W). Berikut ini merupakan nilai vector bobot:

$$
\mathrm{W}=\left[\begin{array}{llllll}
0,15 & 0,15 & 0,15 & 0,15 & 0,2 & 0,2
\end{array}\right]
$$

\section{Tahap Keempat}

Tahap keempat yaitu perangkingan terhadap nilai alternative.

$$
\begin{aligned}
& \mathrm{V} 1=\left(0,15^{*} 0,4\right)+\left(0,15^{*} 0,5\right)+(0,15 * 0,5)+\left(0,15^{*} 0,67\right)+(0,2 * \\
& 1)+(0,2 * 0,4) \\
& =0,06+0,075+0,075+0,1005+0,2+0,08 \\
& =0,5905 \\
& \mathrm{~V} 2=\left(0,15^{*} 1\right)+\left(0,15^{*} 0,67\right)+(0,15 * 1)+(0,15 * 1)+(0,2 * 0,5)+( \\
& 0,2 * 1) \\
& =0,15+0,1005+0,15+0,15+0,1+0,02 \\
& =0,6705 \\
& =0,075+0,1005+0,0375+0,15+0,2+0,12 \\
& =0,683 \\
& =0,075+0,1005+0,045+0,15+0,16+0,1 \\
& =0,6305 \\
& \mathrm{~V} 5=(0,15 * 0,5)+(0,15 * 0,67)+(0,15 * 0,2)+(0,15 * 0,67)+(0,2 \\
& * 0,8)+(0,2 * 0,7) \\
& =0,075+0,1005+0,03+0,1005+0,16+0,14 \\
& =0,606 \\
& \begin{array}{l}
\mathrm{V} 6=(0,15 * 0,67)+(0,15 * 1)+(0,15 * 0,5)+(0,15 * 0,67)+(0,2 * 0 \\
, 6)+(0,2 * 0,8) \\
=0,1005+0,15+0,075+0,1005+0,12+0,16 \\
=0,706
\end{array}
\end{aligned}
$$

Nilai tertinggi terdapat di V6 atau Paket VI merupakan paket yang terpilih sebagai paket terbaik untuk pengguna jasa yang setiap bobot kriterianya ditentukan oleh pengguna jasa.

\section{A. Perancangan Sistem}

1. Use case diagram

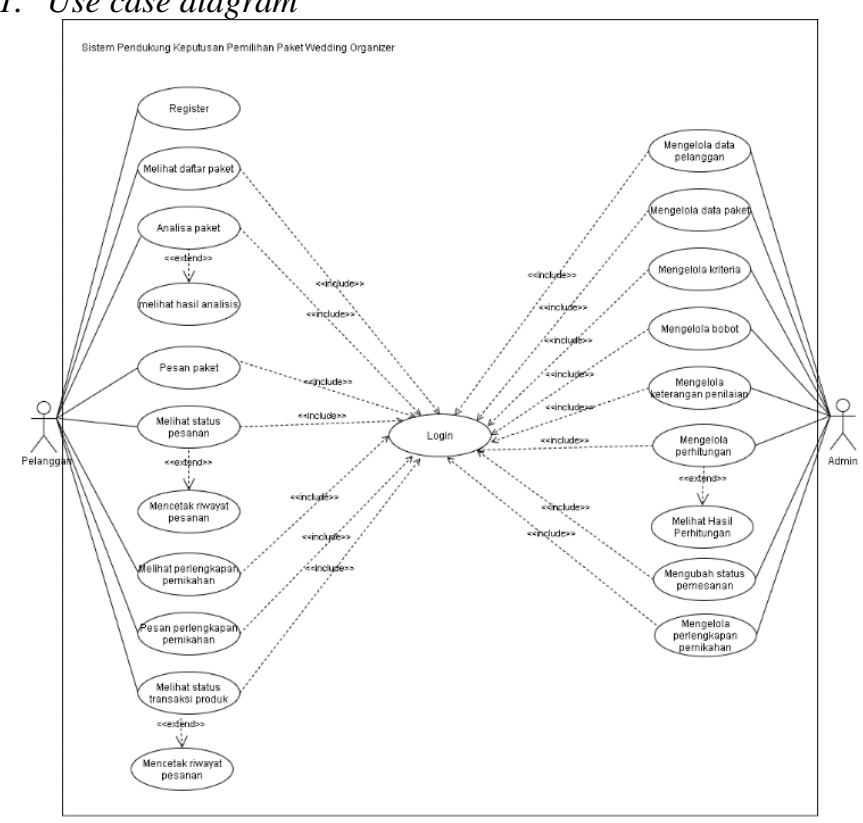

Gambar 2. Use Case Diagram 
Pada gambar 2 menjelaskan use case diagram. Terdapat 2 aktor yaitu admin dan pelanggan. Pelanggan dapat melihat daftar paket, melakukan analisa paket dan melihat hasil analisa paket, memesan paket dan dapat mencetak riwayat pesanan, melihat perlengkapan pernikahan, memesan perlengkapan pernikahan dan dapat mencetak riwayat dari pesanan. Sedangkan admin tugasnya yaitu mengelola data pelanggan, mengelola perhitungan saw dan melihat hasil perhitungan dari pelanggan, mengubah status pesanan, mengelola perlengkapan pernikahan dan mengubah status pesanan.

\section{Class Diagram}

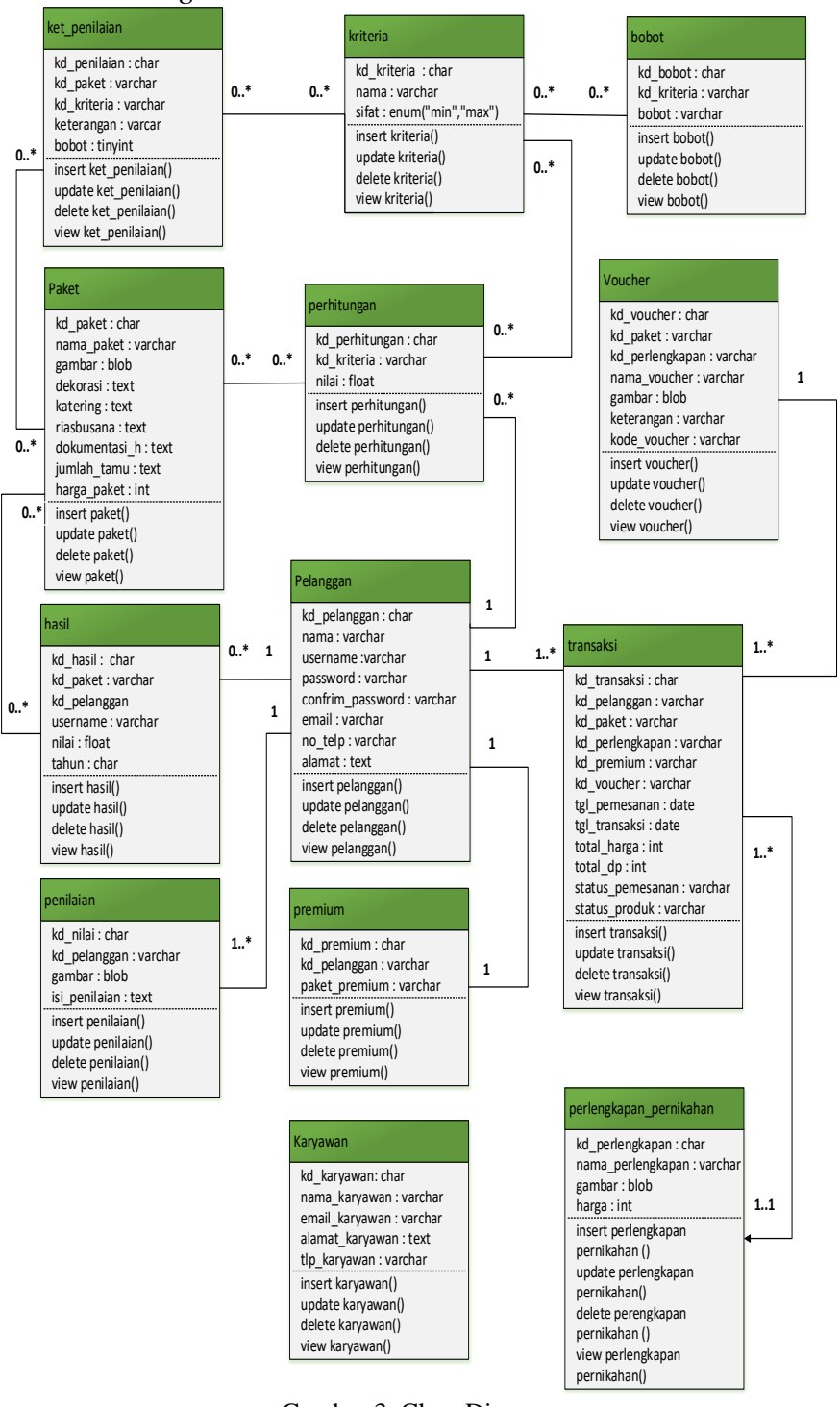

Gambar 3. Class Diagram

Pada gambar 3 merupakan Class Diagram dari perancangan system yang akan dikembangkan. Class diagram ini terdiri dari 13 Class, yaitu Class ket_penilaian, Class kriteria, Class bobot, Class Paket, Class Perhitungan, Class Voucher, Class Hasil, Class Pelanggan, Class Transaksi, Class Penilaian, Class Premium, Class Karyawan, Class Perlengkapan_Pernikahan.

\section{B. Perancangan Antar Muka}

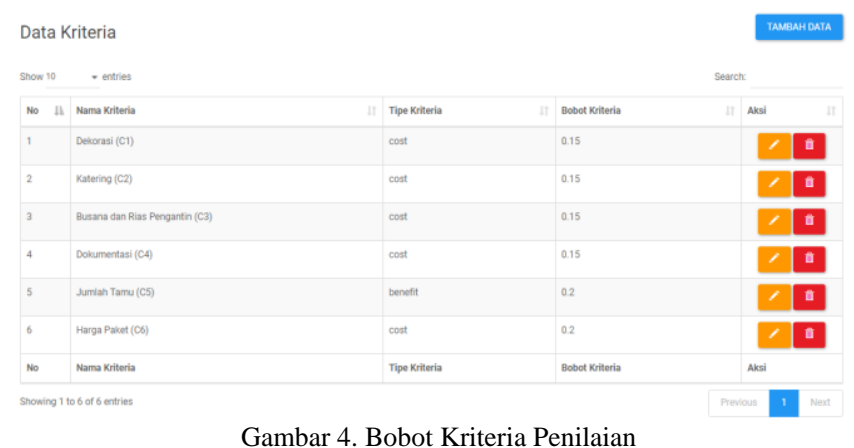

Pada Gambar 4 merupakan halaman bobot kriteria penilaian. Halaman ini berfungsi untuk memberikan bobot atas masing-masing kriteria yang telah ditetapkan.

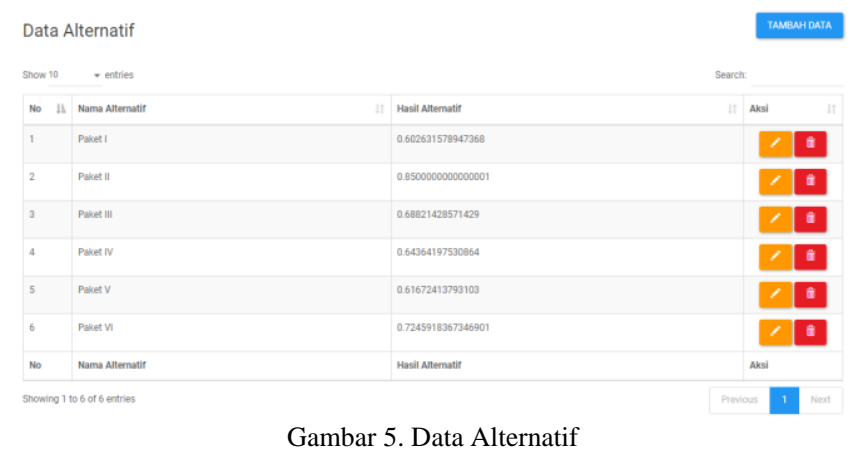

Pada Gambar 5 merupakan halaman data alternatif. Pada halaman ini admin dapat menambah, menginput, atau menghapus alternatif yang ada.

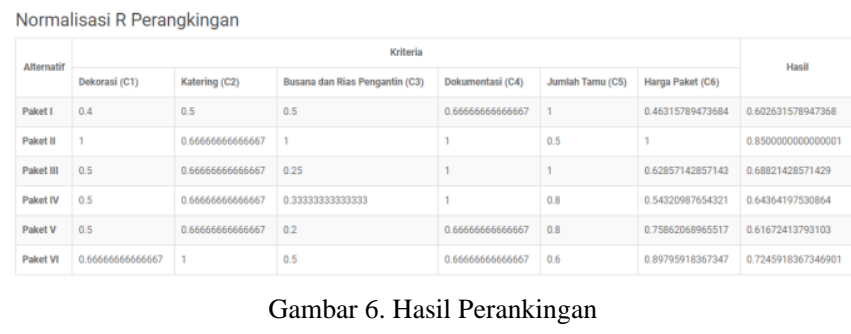

Pada Gambar 6 merupakan halaman Hasil Perankingan. Pada halaman Hasil Perankingan dapat diketahui paket wedding organizer terbaik sesuai dengan kriteria yang telah ditetapkan.

\section{Pengujian Sistem}

Pengujian terhadap perancangan system dilakukan dengan menggunakan metode black-box testing. Black-box testing merupakan salah satu metode dalam pengujian perangkat lunak yang berorientasi pada fungsionalitas system. Pengujian ini dilakukan dengan memberikan input kepada system sehingga mendapatkan output yang diinginkan.

TABLE IV. PengujIan Black BoX

\begin{tabular}{|c|c|c|c|c|}
\hline No. & Pengujian & $\begin{array}{c}\text { Hasil yang } \\
\text { diharapkan }\end{array}$ & $\begin{array}{c}\text { Hasil } \\
\text { Pengujian }\end{array}$ & Kesimpulan \\
\hline 1 & $\begin{array}{c}\text { Simpan } \\
\text { Data }\end{array}$ & $\begin{array}{c}\text { Sistem } \\
\text { menyimpan }\end{array}$ & $\begin{array}{c}\text { Sistem } \\
\text { menyimpan data }\end{array}$ & Diterima \\
\hline
\end{tabular}




\begin{tabular}{|c|c|c|c|c|}
\hline No. & Pengujian & $\begin{array}{c}\text { Hasil yang } \\
\text { diharapkan }\end{array}$ & $\begin{array}{c}\text { Hasil } \\
\text { Pengujian }\end{array}$ & Kesimpulan \\
\hline & Kriteria & $\begin{array}{c}\text { data pada tabel } \\
\text { Kriteria }\end{array}$ & $\begin{array}{c}\text { pada tabel } \\
\text { Kriteria }\end{array}$ & \\
\hline 2 & $\begin{array}{c}\text { Edit Data } \\
\text { Kriteria }\end{array}$ & $\begin{array}{c}\text { Sistem } \\
\text { mengubah data } \\
\text { pada tabel } \\
\text { Kriteria }\end{array}$ & $\begin{array}{c}\text { Sistem } \\
\text { mengubah data } \\
\text { pada tabel } \\
\text { Kriteria }\end{array}$ & Diterima \\
\hline 3 & $\begin{array}{c}\text { Simpan } \\
\text { Data } \\
\text { Alternatif }\end{array}$ & $\begin{array}{c}\text { Sistem } \\
\text { menyimpan } \\
\text { data pada tabel } \\
\text { Alternatif }\end{array}$ & $\begin{array}{c}\text { Sistem } \\
\text { menyimpan data } \\
\text { pada tabel } \\
\text { Alternatif }\end{array}$ & Diterima \\
\hline 4 & Edit Data & $\begin{array}{c}\text { Sistem } \\
\text { mengubah data } \\
\text { pada tabel } \\
\text { Alternatif }\end{array}$ & $\begin{array}{c}\text { Sistem } \\
\text { mengubah data } \\
\text { pada tabel } \\
\text { Alternatif }\end{array}$ & Diterima \\
& & & & \\
\hline
\end{tabular}

\section{KESIMPULAN}

Berdasarkan dari penjelasan dan rumusan masalah, maka dapat membuat kesimpulan yakni dengan adanya perancangan Pemilihan Paket Wedding dapat membantu para pengambilan keputusan untuk mendapatkan hasil penilaian secara cepat. Metode Simple Additive Weighting yang diterapkan dalam rancangan sistem pendukung keputusan dapat memberikan perhitungan perangkingan dan solusi pemilihan paket yang sesuai atau cocok untuk direkomendasikan. Dengan adanya rancangan sistem Pemilihan Paket Wedding organizer membantu para pengambil keputusan dalam masalah pemilihan paket wedding yang tepat berdasarkan kriteria yang diinginkan.

\section{REFERENCES}

[1] S. Destari and B. K. Simpony, "Sistem Pendukung Keputusan Untuk Menentukan Wedding Organizer Menggunakan Metode AHP," Indones. J. Comput. Inf. Technol., vol. 3, no. 2, pp. 197-207, 2018.

[2] S. Mulyati and M. Hisyam, "Rancang Bangun Sistem Informasi Penyewaan Wedding Organizer Berbasis Web Dengan PHP Dan MySQL Pada Kiki Rias,” J. Tek. Univ. Muhammadiyah Tangerang, vol.
7, no. 2, pp. 29-35, 2018.

[3] H. Fuad, A. Budiman, and D. Kurniasari, "Perancangan Sistem Informasi Pemesanan Paket Pernikahan Berbasis Web Study Kasus Di Wedding Organizer PJ Management," Sisfotek Glob., vol. 8, no. 2, pp. 136-141, 2018.

[4] Frieyadie, "Penerapan Metode Simple Additive Weighting dalam Sistem Pendukung Keputusan Promosi Kenaikan Jabatan," J. Pilar Nusa Mandiri, vol. 12, no. 1, pp. 37-45, 2016.

[5] P. P. Rini, Dedi, and N. Riyanti, "Sistem Pendukung Keputusan Pemilihan Dosen Terbaik Berbasis Web Dengan Metode SAW (Simple Additive Weighting) (Studi Kasus: STMIK Global Tangerang)," Sisfotek Glob., vol. 5, no. 2, p. 9, 2015.

[6] D. C. Hartini, E. L. Ruskan, and A. Ibrahim, "Sistem Pendukung Keputusan Pemilihan Hotel Di Kota Palembang Dengan Metode Simple Additive Weighting (Saw)," J. Sist. Inf., vol. 5, no. 1, pp. 546-565, 2013.

[7] Y. Jumaryadi, D. Firdaus, B. Priambodo, and Z. P. Putra, "Determining the Best Graduation Using Fuzzy AHP," 2020 2nd Int. Conf. Broadband Commun. Wirel. Sensors Powering, BCWSP 2020, pp. 59-63, 2020, doi: 10.1109/BCWSP50066.2020.9249463.

[8] M. Nashar, A. Sukamto, and R. D. Parashakti, "Sistem Penunjang Keputusan (Decision Support System DSS) Untuk Pemilihan Karyawan Berprestasi Dengan Metode Simple Additive Weighting (Studi Kasus di Akademi Telekomunikasi Bogor)," J. Ilm. Manaj. dan Bisnis, vol. 2, no. 3, pp. 882-891, 2016.

[9] D. Y. H. Tanjung and R. Adawiyah, "Optimizing Selection of Decision Support System with Fuzzy Simple Additive Weighting," 2018 6th Int. Conf. Cyber IT Serv. Manag. CITSM 2018, no. Citsm, pp. 1-4, 2019, doi: 10.1109/CITSM.2018.8674360.

[10] A. H. Wilarto and U. Salamah, "Sistem Penentuan Penerima Shodaqo Menggunakan Metode Simple Additive Weighting," JUST IT J. Sist. Informasi, Teknol. Inf. dan Komput., vol. 10, no. 2, pp. 123-128, 2020.

[11] H. L. H. S. Warnars, A. Fahrudin, and W. H. Utomo, "Student performance prediction using simple additive weighting method," IAES Int. J. Artif. Intell., vol. 9, no. 4, pp. 630-637, 2020, doi: 10.11591/ijai.v9.i4.pp630-637.

[12] R. S. Pressman and B. Maxim, Software Engineering: A Practitioner's Approach, 8 edition. New York: McGraw-Hill Education, 2014.

[13] M. Mifardi, "Sistem Penunjang Keputusan Pemilihan Paket Pernikahan Menggunakan Metode Simple Additive Weighting (SAW)," J-INTECH, vol. 4 , no. 1 , pp. $1-5,2016$. 